\title{
Knowledge about Health Effects of Cigarette Smoking and Quitting among Italian University Students: The Importance of Teaching Nicotine Dependence and Treatment in the Medical Curriculum
}

\author{
Maria Caterina Grassi, ${ }^{1}$ Massimo Baraldo, ${ }^{2}$ Christian Chiamulera, ${ }^{3}$ Franco Culasso, ${ }^{4}$ \\ Tobias Raupach, ${ }^{5,6}$ Amy K. Ferketich, ${ }^{7}$ Carlo Patrono, ${ }^{8}$ and Paolo Nencini ${ }^{1}$ \\ ${ }^{1}$ Department of Physiology and Pharmacology "V. Erspamer", School of Medicine, Sapienza University of Rome, \\ Piazzale Aldo Moro 5, 00185 Rome, Italy \\ ${ }^{2}$ Department of Experimental and Clinical Medicine, School of Medicine, University of Udine, Piazzale S. Maria della Misericordia, \\ 33100 Udine, Italy \\ ${ }^{3}$ Department of Public Health and Community Medicine, Section of Pharmacology, University of Verona, Policlinico G. B. Rossi, \\ Piazzale Scuro 10, 36134 Verona, Italy \\ ${ }^{4}$ Department of Public Health and Infectious Diseases, School of Medicine, Sapienza University of Rome, Piazzale Aldo Moro 5, \\ 00185 Rome, Italy \\ ${ }^{5}$ Department of Cardiology and Pneumology, University Hospital Göttingen, Robert-Koch-Strasse 40, 37075 Göttingen, Germany \\ ${ }^{6}$ Department of Epidemiology and Public Health, Health Behaviour Research Centre, University College London, 1-19 Torrington Place, \\ London WC1E7HB, UK \\ ${ }^{7}$ Division of Epidemiology, The Ohio State University College of Public Health, 1841 Neil Ave, 310 Cunz Hall, Columbus, \\ OH 43210, USA \\ ${ }^{8}$ Department of Pharmacology, School of Medicine, Catholic University of Rome, Largo F. Vito 1, 00168 Rome, Italy
}

Correspondence should be addressed to Maria Caterina Grassi; caterina.grassi@uniromal.it

Received 4 February 2014; Accepted 25 February 2014; Published 6 April 2014

Academic Editor: Giuseppe La Torre

Copyright (C) 2014 Maria Caterina Grassi et al. This is an open access article distributed under the Creative Commons Attribution License, which permits unrestricted use, distribution, and reproduction in any medium, provided the original work is properly cited.

Aims of the study were to compare medical students (MS) to non-MS with respect to their knowledge of smoking and to investigate the effect of a short educational intervention on MS knowledge. MS $(n=962)$ and students of architecture and law $(n=229)$ were asked to complete a 60-item questionnaire addressing knowledge of smoking epidemiology and health effects ("Score 1"), and effectiveness of cessation treatments ("Score 2"). Upon completion of questionnaire, fourth year MS received a lecture on tobacco dependence. These students were asked to complete the same questionnaire one and two years later. Mean values for Score 1 were $48.9 \pm 11.5 \%$ in MS and $40.5 \pm 11.4 \%$ in non-MS $(P<0.001 ; d=0.69)$. Respective values for Score 2 were $48.1 \pm 10.8 \%$ and $42.6 \pm 10.6 \%(P<0.001 ; d=0.50)$. Fifth year students who had attended the lecture in year 4 scored higher than students who had not attended the lecture. Significant differences were noted one but not two years after the educational intervention. In conclusion, MS know slightly more about smoking-related diseases and methods to achieve cessation than nonmedical students; a short educational intervention was associated with better knowledge one year later, but the effect was moderate and short-lived.

\section{Introduction}

Tobacco smoking is the leading cause of preventable death in developed countries and is the most important risk factor for cancer worldwide, responsible for approximately
$22 \%$ of all cancer deaths per year $[1,2]$. According to the Osservatorio Fumo, Alcol e Droga, about 11 million adults in Italy are still current smokers, $20.7 \%$ of the entire adult population [3]. Smoking is the largest avoidable health risk in Europe, causing more problems than alcohol, drugs, 
high blood pressure, excess weight, or high cholesterol (http://ec.europa.eu/health/tobacco/policy/index_en.htm). Consequently, every year, 695,000 Europeans die prematurely of tobacco-related diseases and it is estimated that, within the EU, smoking causes annual costs of at least $€ 100$ billion (http://ec.europa.eu/health/tobacco/docs/eurobaro_attitudes_towards_tobacco_2012_en.pdf). Conversely, smoking cessation reduces health risks and improves quality of life. In particular, the cumulative risk of dying of cancer, cardiovascular and lung diseases can be drastically reduced if smokers quit, even at an advanced age [4-6]. There is no doubt that medical advice helps smokers quit [7], yet often this opportunity is missed [8-10]. The frequent observation of general practitioners (GPs) not adhering to guidelines for brief counseling might at least partially be due to inadequate training in undergraduate education. Indeed, substantial deficiencies in medical education on smoking-related issues have been described [11-15]. This is not surprising since little attention is being paid to nicotine dependence in medical school curricula; a worldwide survey recently revealed that only one in four medical schools taught a specific module on nicotine dependence [16].

Recent studies on medical education in various European countries have consistently shown that undergraduate training in this area is insufficient. This is surprising when considering that well-conceived educational interventions to improve knowledge, skills, and attitudes of medical students regarding the treatment of smokers are available $[17,18]$. Arguably, one factor limiting the implementation of such programs is their high cost in terms of resources and teacher time. Therefore, there is a need for straightforward and relatively simple but yet effective tobacco curricula. For instance, even one single lecture on the topic might be enough to stir the interest of students eliciting self-directed learning activities with regard to tobacco toxicology and treatment options. More high-quality research in this area is clearly needed [19].

We recently reported that Italian students attending the fourth year of undergraduate medical education have limited knowledge about tobacco dependence, smokingrelated pathologies, and the role of physicians in promoting smoking cessation [20]. While these findings in themselves are a cause for concern, their interpretation might be further enhanced by comparing them to survey results obtained from nonmedical students. Since medical education needs to prepare future physicians for their role as health advocates, one would expect medical students to know substantially more about smoking and cessation than students of nonmedical professions. However, to the best of our knowledge, nonmedical students have rarely been surveyed with regard to their knowledge about tobacco.

Based on these considerations, the aims of this study were to (i) verify the consistency of our previous findings [20], (ii) assess whether nonmedical students of the same age have different perceptions and knowledge about smoking compared to medical students, and (iii) monitor knowledge retention of tobacco dependence and medical students smoking status, one and two years following a short educational intervention.

\section{Methods}

2.1. Questionnaire. Students were asked to complete a 60item questionnaire, previously validated [20], derived from studies on this topic $[21,22]$. The questionnaire was composed of four main sections:

(i) demographics and personal smoking history: gender, age, age at initiation, cessation history, intention to quit, and nicotine dependence using the Fagerström Test for Nicotine Dependence (FTND) [23],

(ii) knowledge of smoking-related epidemiologic facts: knowledge of smoking attributable mortality, tobacco toxins, health risks associated with smoking, and the benefits of smoking cessation,

(iii) knowledge of clinical guidelines on tobacco dependence treatment, as well as competence in counseling a smoker seeking help to give up smoking,

(iv) perception of the influence of smoking on life expectancy: students were asked whether they personally knew smokers and nonsmokers who had lived to the age of 90 years (total 2 questions). One further question was asked about knowledge of tobacco treatment centers in the city of their university and one final question was asked to students, "Would you like a smoke-free university?" Response options were "yes" or "no."

To assess the knowledge of tobacco and cessation, two scores were computed. "Score 1" was based on responses to questions on the epidemiology of smoking and related risks, as well as on the benefits of quitting smoking; "Score 2" was based on responses to questions about nicotine dependence treatments and their effectiveness (see data analysis for the details of scores computing). For a detailed description of the questionnaire, see our previous paper [20]. The questionnaire is available upon request.

2.2. Study Participants. Students from four different medical schools and one school of architecture and law were invited to participate in the study. Two of the four medical schools (Sapienza University of Rome, Catholic University, Rome Campus) as well as the Schools of Architecture and Law (Sapienza University of Rome) were located in Rome whereas the other two medical schools were located in Northern Italy (University of Udine and University of Verona). All medical schools involved offered a standard core curriculum representative of that given by other medical schools in Italy, in which drug addiction is a topic of the fourth year. In this year preclinical courses are dealing with general and specific health risks including cigarette smoking. In order to address the three study aims, students were divided into eight different groups as described below.

Study Question 1. "Does the questionnaire produce consistent results in consecutive cohorts of medical students?" To answer this study question, fourth year medical students from two consecutive cohorts (2010: Group 1; 2011: Group 2) were invited to participate in the study. Students in both cohorts 


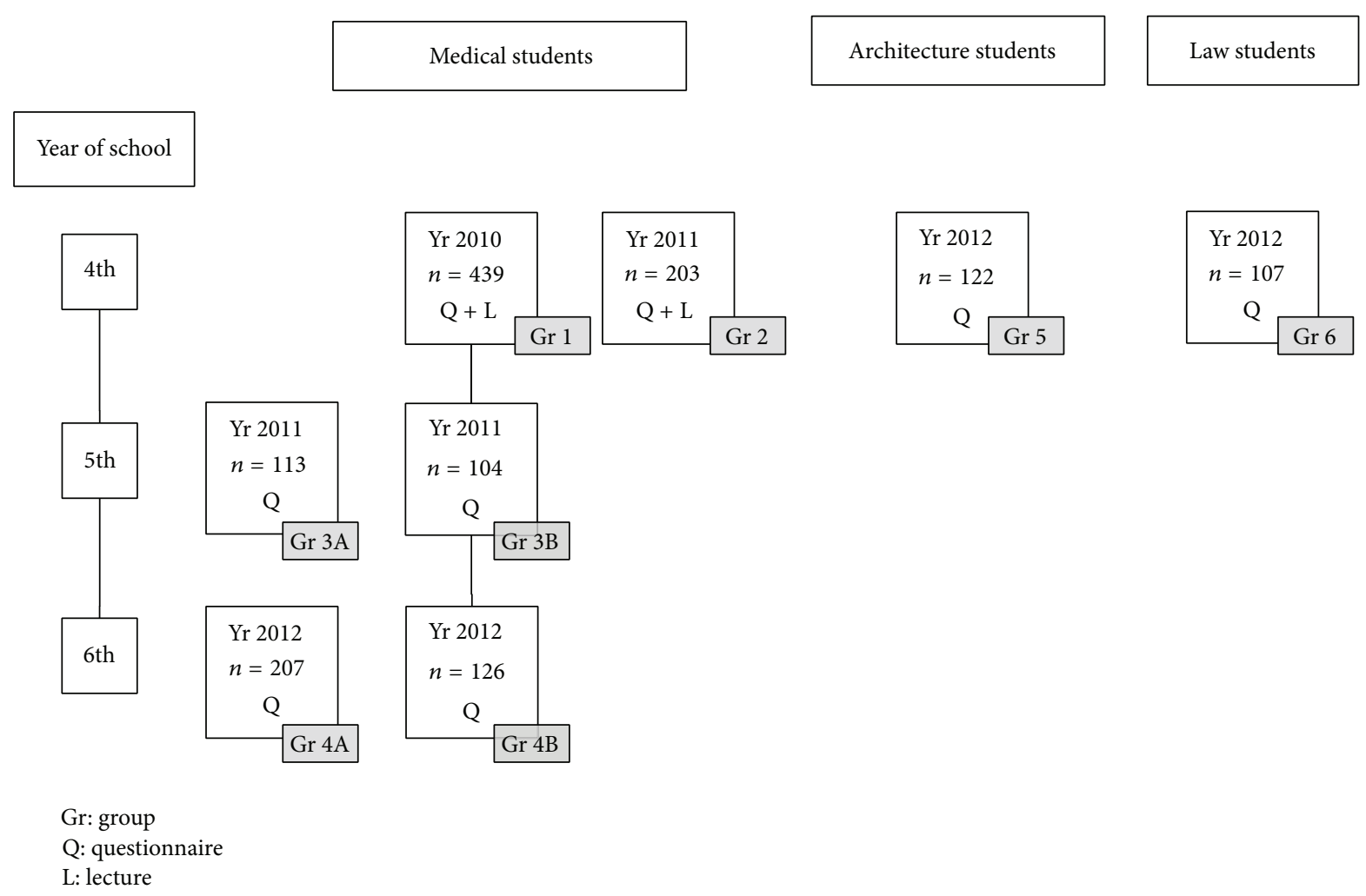

FIGURE 1: Chart of the different groups of 1191 students enrolled in the study according to year of school, university school, and intervention on nicotine dependence (questionnaire and lecture or questionnaire only).

were enrolled in the course of pharmacology and toxicology and completed the questionnaire before attending a lecture on nicotine dependence.

Study Question 2. "Do nonmedical students of the same age have different perceptions and knowledge about smoking compared to medical students?" To answer this study question, two cohorts of fourth year students studying architecture (Group 5) and law (Group 6) were invited to complete the study questionnaire in 2012 and were compared with fourth year medical students (Group 1 and Group 2).

Study Question 3. "How much knowledge of nicotine dependence is retained by medical students one and two years following a short educational intervention?" To answer this study question, the 2010 student cohort was followed up for 2 years (2011: Group 3; 2012: Group 4). Each year, students completed the same questionnaire. While doing so, they were asked whether they had attended the lecture in 2010. Based on their replies, students were labelled as being in the "control" (neither questionnaire nor lecture: Groups $3 \mathrm{~A}$ and $4 \mathrm{~A}$ ) or "intervention" (questionnaire + lecture: Groups 3B and 4B) cohorts.

For more information on the flow of participants through the study and sample sizes, please see Figure 1.

2.3. Data Collection. Between April 2010 and November 2012, students attending the academic courses were invited to complete the questionnaire; participation was voluntary and anonymous. After having explained the purpose of the study, a pharmacology lecturer distributed the questionnaire and students were allowed 30 minutes to complete it. Lecturers remained in the room but kept at a distance from participating students in order to ensure anonymity of the responses. In the case of students attending the course of pharmacology and toxicology, offered only to the fourth year in all participating medical schools, a teaching lecture based on specific protocol, dealing with epidemiology of smokingrelated diseases, health risk of smoking, and nicotine dependence and its treatment, was delivered by the pharmacology teacher, after questionnaire completion.

2.4. Data Analysis. As previously described [20], the questionnaire contained 46 close-ended questions and 1 openended question, for a total of 60 items, since some questions consisted of more than 1 item. Ten questions (14 items) were used to calculate Score 1 whereby each answer was assigned a value between 0 and 2 (range $0-28$ ). A value of 2 implied that the students answered correctly, a value of 1 implied that the answer was in the $10 \%$ range of a quantal response, and a value of 0 implied a totally incorrect answer. Questions that were not answered were counted as incorrect answers. The items for Score 1 included (i) smoking epidemiology; (ii) risks associated with smoking; and (iii) benefits of cessation. Using nine additional questions (14 items), another Score 2 was computed, assigning a value of 0 to 2 to each answer 
(same mechanism for assigning values for Score 1), to evaluate students based on their knowledge of (i) clinical guidelines on smoking cessation; (ii) effectiveness of smoking cessation methods.

Descriptive statistics were performed for each question. Since all data were collected anonymously, we were unable to match individual student data obtained in the 2010 cohort to subsequent surveys in this longitudinal cohort. Thus, all groups were treated as independent groups, and analysis of variance (ANOVA) was performed to assess significant differences between groups, followed by post hoc Bonferroni corrections for study questions 1 and 3 . Student's $t$ test was used to compare mean values obtained from the two groups (study question 2). Cohen's $d$ effect sizes were calculated.

For dichotomous variables, chi-square tests were performed. Differences were considered statistically significant at a $P$ value $<0.05$. Statistical analyses were performed using SPSS Version 20.0 for Mac.

Approval of the study method was obtained from the Ethics Committee of the Hospital Policlinico Umberto I, at Sapienza University of Rome, as well as from the Dean of each of the other participating medical and nonmedical schools.

\section{Results}

The questionnaire was completed by 1191 students, 962 of whom were medical students (61\% female, mean age $23.9 \pm$ 2.8 years, range $20-55), 122$ studied architecture (57\% female, mean age $23.2 \pm 3.4$ years, range $20-41)$, and the remaining 107 studied law $(72 \%$ female, mean age $21.7 \pm 2.0$ years, range 20-38). All the students present in the class agreed to complete the questionnaire. Questionnaire completion was satisfactory, as the response rate was of $100 \%$, missing items were fewer than $10 \%$, and the proportion of missing values did not differ significantly between groups.

3.1. Demographic Characteristics, Personal History of Tobacco Use, and Intention to Quit. As shown in Table 1, self-reported current smoking was significantly higher $(P<0.01)$ among architecture (26.2\%) and law (26.2\%) students compared to medical students $(16.9 \%)$. Among the latter, the percentage of current smokers was significantly higher in males than females $(22.0 \%$ versus $13.6 \% ; P=0.001)$. A similar gender difference was observed among architecture and law students, although statistical significance was not reached (architecture: $29.4 \%$ versus $25.4 \%$; law: $33.3 \%$ versus $24.0 \%$ ). Smoking students scored low on the FTND, and the majority $(66.8 \%)$ smoked less than 10 cigarettes per day and wanted to stop smoking (57.9\%). A particularly low smoking prevalence was noted in the 6 th year medical students who had attended the lecture on nicotine dependence during their fourth year (2010 cohort; Group 4B). Their smoking prevalence of $10.3 \%$ was less than half of that found in sixth year students who had missed the lecture (Group 4A: $23.7 \% ; P=0.001$ ). Only onefifth of the smoking students $(22.3 \%$ of medical and $18.3 \%$ of nonmedical students) reported having received advice to stop smoking by a GP during the past year.
3.2. Smoking and Life Expectancy, Wishing a Smoke-Free University, and Knowledge of Tobacco Treatment Centers. As expected from our previous work [20], we found that the percentage of medical students claiming they personally knew a smoker who had lived to the age of 90 years was significantly greater in smokers than in nonsmokers $(55.8 \%$ versus $39.8 \%$; $P<0.01$ ), whereas the percentage of students answering that they personally knew a nonsmoker who had reached the age of 90 years was similar in smokers and nonsmokers (87.3\% smokers versus $87.1 \%$ nonsmokers) with no statistically significant differences between the six groups considered.

The vast majority of nonsmoking medical students (91.4\%) claimed they would like to study in a smoke-free university while this view was only supported by $48.2 \%$ of smokers $(P<0.001)$. The corresponding figures for architecture and law students were $78.9 \%$ versus $15.6 \%(P<$ $0.001)$ and $79.7 \%$ versus $35.7 \%(P<0.001)$, respectively.

Finally, $40.4 \%$ of fifth year medical students in Group 3B, $16.7 \%$ of sixth year medical students in Group $4 \mathrm{~B}, 11.3 \%$ of those in Groups 1, 2, 3A, and 4A, and only $2.6 \%$ of nonmedical studentswere aware of the existence of tobacco treatment centers in the city of their university.

\subsection{Comparisons between Student Groups}

3.3.1. Study Question 1. As shown in Figure 2, fourth year medical students had limited knowledge of the epidemiology of smoking, in terms of attributable morbidity and mortality, and of the benefits of stopping smoking (Score 1), before attending the educational intervention, with no statistically significant differences between groups. We also confirmed that knowledge of clinical guidelines on nicotine dependence treatment, perceived competence in both counseling and treating smokers was insufficient (Score 2), with no statistically significant differences between groups.

3.3.2. Study Question 2. In order to address study question 2, only data obtained from fourth year students were included in the analysis. Medical students survey data were collected in 2010 (Group 1) and 2011 (Group 2) while nonmedical students data were collected in 2012 (Groups 5 and 6). Mean values for Score 1 were $48.9 \pm 11.5 \%$ in medical students and $40.5 \pm 11.4 \%$ in nonmedical students $(P<0.001$; effect size $d=0.69$ ). Respective values for Score 2 were $48.1 \pm 10.8 \%$ and $42.6 \pm$ $10.6 \%(P<0.001 ; d=0.50)$. These results suggest that the choice and attendance of a medical school are associated with marginal improvement in these parameters.

3.3.3. Study Question 3. In 2011, there were statistically significant differences in knowledge levels between those who had attended the lecture in 2010 (Group 3B) and those who had missed it (Group 3A). This was true for Score 1 (55.0 \pm $12.7 \%$ versus $50.5 \pm 11.6 \%, P=0.01$; effect size $d=0.37)$ as well as for Score $2(55.4 \pm 13.7 \%$ versus $49.7 \pm 11.0 \%, P=0.001$; effect size $d=0.46)$. However, no significant differences were observed in 2012 (i.e., two years after attending versus missing the lecture; see Figure 2 and Table 2). 


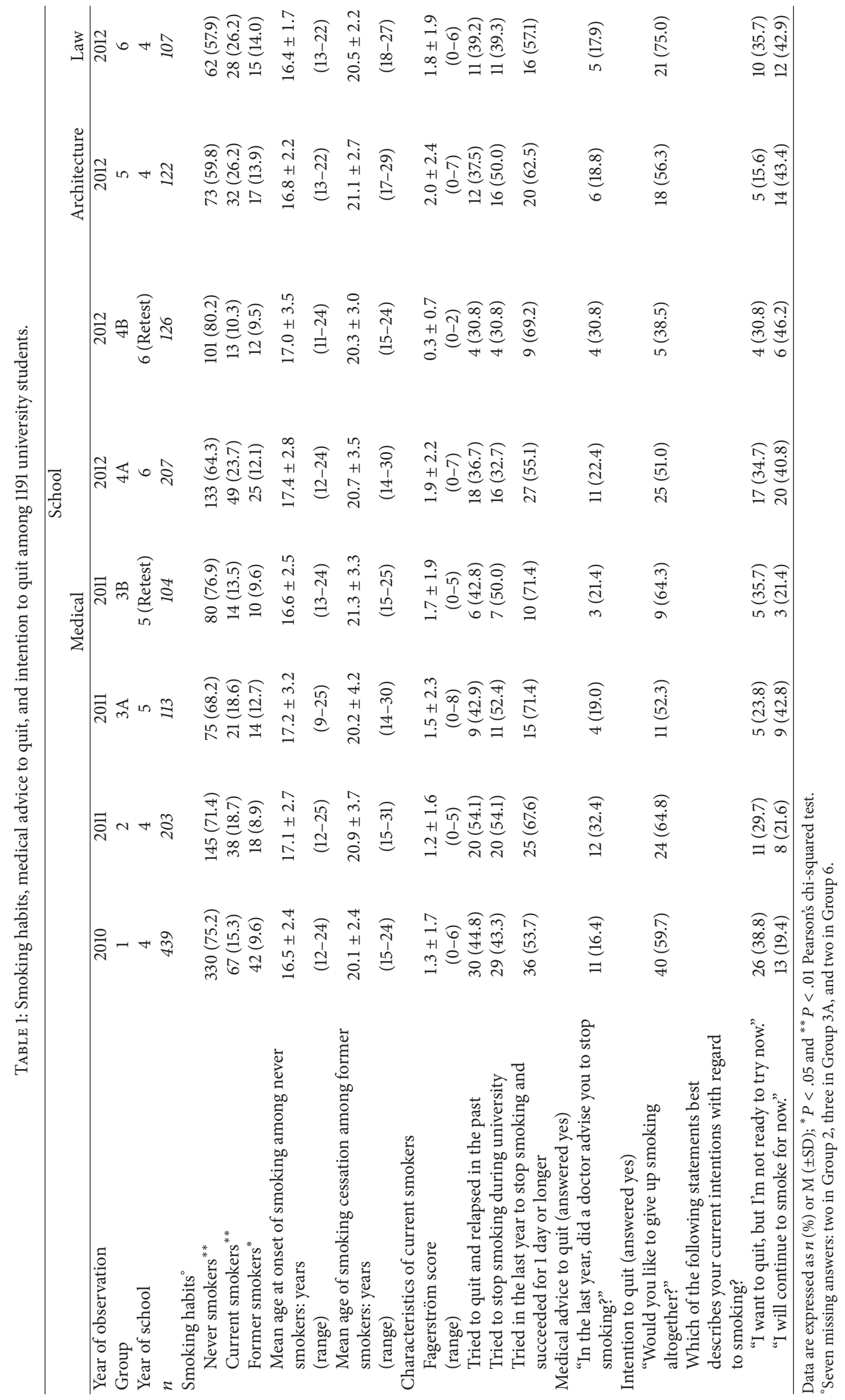


Score 1

Smoking epidemiology, risks associated with smoking, and benefits of cessation

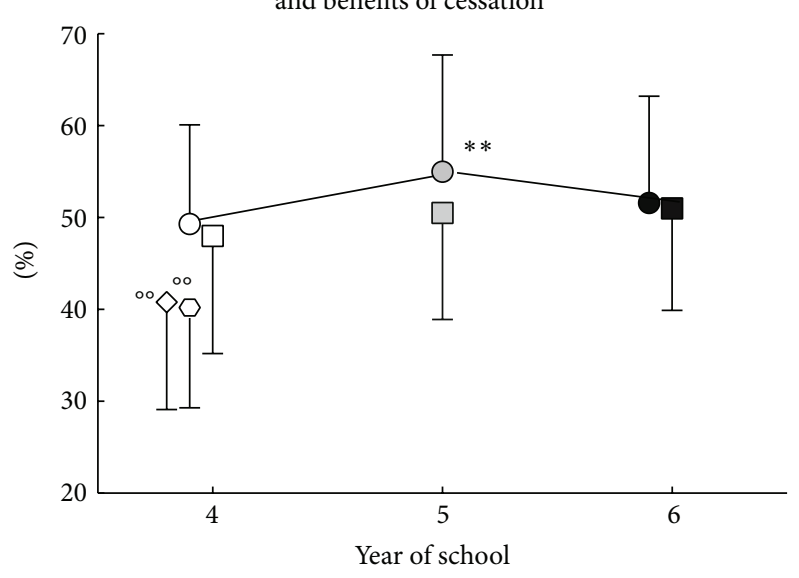

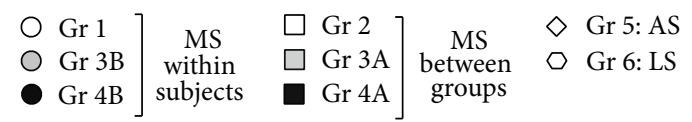

MS: medical students

AS: architecture students

LS: law students

${ }^{* *} p<0.01$, Gr $3 \mathrm{~B}$ versus Gr 1 and Gr 2

${ }^{\circ} p<0.01, \mathrm{Gr} 5$ and Gr 6 versus each group of MS (Bonferroni)

(a)

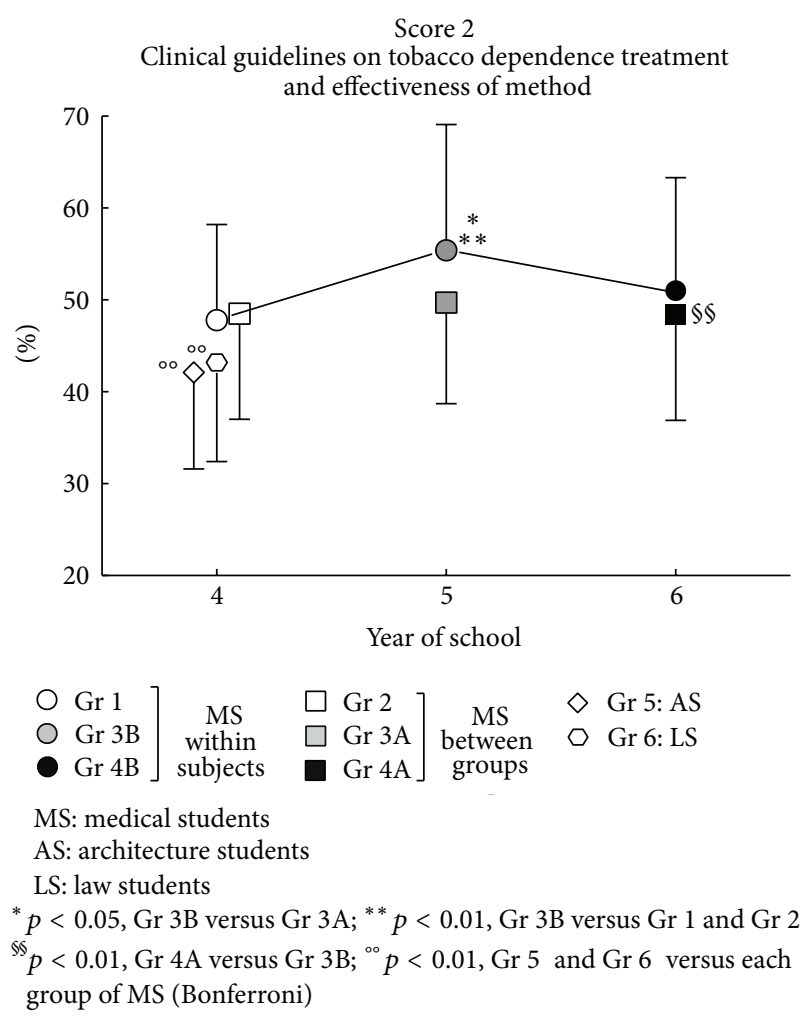

(b)

FIGURE 2: Scores of knowledge in medical students without or with a previous education intervention on nicotine dependence and in fourth year nonmedical students.

TABLE 2: Mean scores for two sets of 14 grouped items in 1191 university students.

\begin{tabular}{|c|c|c|c|c|c|c|c|c|c|}
\hline \multirow[b]{3}{*}{ Year of observation } & \multicolumn{8}{|c|}{ School } & \multirow[t]{2}{*}{$P$ value $^{\mathrm{a}}$} \\
\hline & \multicolumn{6}{|c|}{ Medical } & \multirow{2}{*}{$\frac{\text { Architecture }}{2012}$} & \multirow{2}{*}{$\frac{\text { Law }}{2012}$} & \\
\hline & 2010 & 2011 & 2011 & 2011 & 2012 & 2012 & & & \\
\hline Group & 1 & 2 & $3 \mathrm{~A}$ & $3 \mathrm{~B}$ & $4 \mathrm{~A}$ & $4 \mathrm{~B}$ & 5 & 6 & \\
\hline Year of school & 4 & 4 & 5 & 5 (retest) & 6 & 6 (retest) & 4 & 4 & \\
\hline Total sample $(n)$ & 439 & 203 & 113 & 104 & 207 & 126 & 122 & 107 & \\
\hline \multicolumn{9}{|c|}{ Knowledge of smoking epidemiology, risks associated with smoking, and benefits of cessations: Score 1} & \multirow{4}{*}{$<.001$} \\
\hline$n$ & 393 & 180 & 103 & 97 & 189 & 120 & 109 & 95 & \\
\hline Mean (SD) & $49.3(10.8)$ & $47.9(12.8)$ & $50.5(11.6)$ & $55.0(12.7)$ & $51.0(11.1)$ & $51.6(11.6)$ & $40.8(11.7)$ & $40.2(10.9)$ & \\
\hline Range (0-100) & $17-87$ & $17-87$ & $23-70$ & 27-87 & $23-80$ & $20-83$ & $17-77$ & $20-67$ & \\
\hline \multicolumn{9}{|c|}{ Knowledge of clinical guidelines on tobacco dependence treatment and effectiveness of method: Score 2} & \multirow{4}{*}{$<.001$} \\
\hline$n$ & 391 & 182 & 103 & 98 & 191 & 118 & 105 & 92 & \\
\hline Mean (SD) & $47.8(10.4)$ & 48.8 (11.5) & 49.7 (11.0) & $55.4(13.7)$ & $48.4(11.5)$ & $51.0(12.3)$ & $42.1(10.5)$ & $43.2(10.8)$ & \\
\hline Range (0-100) & 7-87 & $17-87$ & 30-77 & 23-87 & 17-77 & $20-80$ & $20-67$ & $13-70$ & \\
\hline
\end{tabular}

$n$ : number of subjects observed.

${ }^{\mathrm{a}}$ Analysis of variance.

\section{Discussion}

The present study confirms and extends our previous observation about the inadequate knowledge among medical students of nicotine dependence and provides two additional novel findings. Thus, our findings in the 2010 cohort that had previously been reported [20] were confirmed in a subsequent albeit smaller sample of fourth year medical students (Group 2). This is important since, due to a limited sample size in our earlier study, we were unable to exclude confounding of our results by selection bias. Moreover, we found that knowledge scores in nonmedical students were significantly lower than in medical students; however, the difference appeared relatively small when considering 
that the latter had already received three years of medical education. The knowledge levels observed in nonmedical students are likely to reflect general knowledge levels in well-educated young adults. A mean difference of only $10 \%$ points between medical and nonmedical students indicates a substantial failure of medical education in providing medical students with better knowledge of a fundamental issue of disease prevention than a general student population. Finally, medical students attending a lecture on nicotine dependence did better in a follow-up test one year later than students who had not been exposed to this intervention. Unfortunately, this difference between "intervention" and "control" groups was lost two years later.

The finding that a single lecture significantly improved the knowledge about tobacco-related issues one year later is of considerable interest and is consistent with similar results obtained in other medical disciplines. In particular, giving a single teaching lecture on a specific medical issue [24-26] has been found to permanently improve the ability to deal with those medical problems. Unfortunately, differences in knowledge seemed to be transient in as far as scores were back to baseline levels two years later. Yet, it is interesting to note that, even two years after the intervention, this group of students showed a smoking prevalence of $10.3 \%$ and the lowest FTND scores among groups. However, this result may also be explained by selection bias favouring students who were interested in the topic, thus being more motivated to complete the questionnaire again. Incidentally and in agreement with previous observations [27], all smoking students scored low at FTND; the lowest values were found in medical students.

Smoking prevalence among medical students was lower (16.9\%) with respect to both the Italian population $(20.7 \%)$ [3] and their colleagues of architecture and law school (26.3\%). As smoking status was not biochemically validated, there is a possibility that smoking prevalence was underestimated in medical students. One potential explanation for this is selection bias in that smoking students might have been less likely to attend the lecture in the first place. Secondly, the students sampled may not be representative of all Italian medical students. Thirdly, according to the effect of social desirability, smoking medical students may have been more likely to misreport their smoking status as they felt it would be inappropriate for future physicians to be smoking. At the same time, our findings could actually reflect true smoking prevalence, as nonsmokers may be more likely to study medicine. Given the uncertainty associated with selfreports of smoking status, we refrained from conducting subgroup analyses or running statistical models including smoking status as a moderating variable.

As discussed above, our educational intervention that consisted of a single lecture on nicotine dependence was associated with higher knowledge levels one year after the intervention. A combination of educational and interactive training during medical school improves knowledge, attitude, and counselling skills on tobacco cessation and behavioural change $[28,29]$. Role-playing and interaction with patients are equally effective and both represent more powerful learning tools than web-based learning with or without a teaching lecture [30]. Yet, overcrowded core curricula in many medical schools limit the possibility of extended training, and perhaps the most parsimonious strategy may consist in educating clinical teachers to mention tobacco toxicology whenever the possibility arises. This could be a cost-effective and efficient way of improving knowledge.

Thus, our results provide the rationale for studies comparing the effects of a single educational intervention with those yielded by a more comprehensive training in the health consequences of smoking. Interestingly, recent research has revealed that the choice of the educational method is far less important for student learning than summative assessments. As a consequence, medical students should undergo valid summative assessments of their knowledge of nicotine dependence [31].

In our opinion, the present study has five main limitations: (i) we included medical students from only four Italian universities; therefore, our sample is not fully representative of the entire population of Italian medical students; (ii) attrition substantially reduced to approximately one-fourth the number of students that were retested in the fifth and sixth years; thus, selection bias favoring the subsequent participation of students with higher interest levels in tobaccorelated issues and higher motivation might have skewed our results; (iii) the sample size of architecture and law students was relatively small, questioning the representativeness of our findings in these groups; (iv) smoking status of participating students was only assessed by means of self-report so that smoking prevalence might have been underestimated; (v) we could not track individuals and their change in responses since we did not include identifying information.

\section{Conclusions}

In summary, this study revealed that Italian undergraduate medical students have marginally higher knowledge about smoking-related disease and methods to achieve cessation than students of nonmedical schools. Attending a lecture on nicotine dependence was associated with slightly better knowledge one year later, but the effect was moderate and short-lived. Greater efforts are needed to educate a generation of physicians that will have to deal with the consequences of the smoking epidemic in the 21st century.

\section{Ethical Approval}

This work was approved by the Ethics Committee of the Hospital Policlinico Umberto I, at Sapienza University of Rome, as well as by the Dean of each of the other participating medical and nonmedical schools.

\section{Conflict of Interests}

The authors declare that there is no conflict of interests.

\section{Authors' Contribution}

Maria Caterina Grassi, Massimo Baraldo, and Christian Chiamulera conceived the research and delivered the educational lecture; Maria Caterina Grassi, Massimo Baraldo, 
Christian Chiamulera, and Carlo Patrono participated in data collection and analysis and interpretation of the results; Maria Caterina Grassi, Franco Culasso, and Amy K. Ferketich elaborated the data; Maria Caterina Grassi, Massimo Baraldo, Christian Chiamulera, Tobias Raupach, and Paolo Nencini drafted the paper; all authors revised and approved the paper.

\section{Acknowledgments}

The authors are grateful to Piero Mancini for his help in creating the database and analysis of the data and to Francesca Zanusso for her help in entering the data. The study was supported by a grant from Sapienza University of Rome.

\section{References}

[1] World Health Organization (WHO), "The MPOWER: a policy package to reverse the tobacco epidemic," Tech. Rep., Health Organization press, Geneva, Switzerland, 2008, http:// www.who.int/tobacco/mpower/mpower_english.pdf.

[2] World Health Organization (WHO), "Cancer Fact sheet no. 297," 2013, http://www.who.int/mediacentre/factsheets/fs297/ en/index.html.

[3] Osservatorio Fumo and Alcol e Droga (OssFAD), "Relazione annuale sul tabagismo. Indagine DOXA," Annual Report on Tobacco Use, Istituto Superiore di Sanità, Roma, The DOXA study, 2013, http://www.iss.it/fumo/rann/cont.php?id=195\& lang=1\&tipo=3.

[4] P. Jha, C. Ramasundarahettige, V. Landsman et al., "21st-century hazards of smoking and benefits of cessation in the United States," The New England Journal of Medicine, vol. 368, no. 4, pp. 341-350, 2013.

[5] M. J. Thun, B. D. Carter, D. Feskanich et al., "50-year trends in smoking-related mortality in the United States," The New England Journal of Medicine, vol. 368, no. 4, pp. 351-364, 2013.

[6] K. Pirie, R. Peto, G. K. Reeves, J. Green, V. Beral, and Million Women Study Collaborators, "The 21st century hazards of smoking and benefits of stopping: a prospective study of one million women in the UK," The Lancet, vol. 381, no. 9861, pp. 133-141, 2013.

[7] M. C. Fiore, C. R. Jaén, T. B. Baker et al., "Treating tobacco use and dependence: 2008 update. Clinical practice guideline," Tech. Rep., U.S. Department of Health and Human Services. Public Health Service, Rockville, MD, 2008, http:// www.surgeongeneral.gov/tobacco/treating_tobacco_use08.pdf.

[8] L. F. Stead, G. Bergson, and T. Lancaster, "Physician advice for smoking cessation," Cochrane Database of Systematic Reviews, no. 2, Article ID CD000165, 2008.

[9] A. K. Ferketich, S. Gallus, P. Colombo et al., "Physiciandelivered advice to quit smoking among Italian smokers," The American Journal of Preventive Medicine, vol. 35, no. 1, pp. 6063, 2008.

[10] N. A. Zwar, R. L. Richmond, D. Davidson, and I. Hasan, "Postgraduate education for doctors in smoking cessation," Drug and Alcohol Review, vol. 28, no. 5, pp. 466-473, 2009.

[11] M. C. Fiore, R. P. Epps, and M. W. Manley, "A missed opportunity. Teaching medical students to help their patients successfully quit smoking," Journal of the American Medical Association, vol. 271, no. 8, pp. 624-626, 1994.
[12] R. L. Richmond, D. S. Debono, D. Larcos, and L. Kehoe, "Worldwide survey of education on tobacco in medical schools," Tobacco Control, vol. 7, no. 3, pp. 247-252, 1998.

[13] L. H. Ferry, L. M. Grissino, and P. S. Runfola, "Tobacco dependence curricula in US undergraduate medical education," Journal of the American Medical Association, vol. 282, no. 9, pp. 825-829, 1999.

[14] B. Kusma, D. Quarcoo, K. Vitzthum et al., "Berlin's medical students' smoking habits, knowledge about smoking and attitudes toward smoking cessation counseling," Journal of Occupational Medicine and Toxicology, vol. 5, no. 1, article 9, 2010.

[15] T. Raupach, L. Strobel, E. Beard, H. Krampe, S. Anders, and R. West, "German medical students' beliefs about the effectiveness of different methods of stopping smoking," Nicotine and Tobacco Research, vol. 15, no. 11, pp. 1892-1901.

[16] R. Richmond, N. Zwar, R. Taylor, J. Hunnisett, and F. Hyslop, "Teaching about tobacco in medical schools: a worldwide study," Drug and Alcohol Review, vol. 28, no. 5, pp. 484-497, 2009.

[17] F. T. Leone, S. Evers-Casey, J. Veloski, A. A. Patkar, and L. Kanzleiter, "Short-, intermediate-, and long-term outcomes of Pennsylvania's continuum of tobacco education pilot project," Nicotine and Tobacco Research, vol. 11, no. 4, pp. 387-393, 2009.

[18] R. Richmond and R. Taylor, "Global dissemination of a tobacco curriculum in medical schools," International Journal of Tuberculosis and Lung Disease, vol. 10, no. 7, pp. 750-755, 2006.

[19] T. Raupach, H. Krampe, and J. Brown, "Does research into medical education on tobacco and alcohol get the respect it deserves?" Addiction, vol. 109, no. 2, pp. 173-174, 2014.

[20] M. C. Grassi, C. Chiamulera, M. Baraldo et al., "Cigarette smoking knowledge and perceptions among students in four Italian medical schools," Nicotine and Tobacco Research, vol. 14, no. 9, pp. 1065-1072, 2012.

[21] T. Raupach, L. Shahab, S. Baetzing et al., "Medical students lack basic knowledge about smoking: findings from two European medical schools," Nicotine and Tobacco Research, vol. 11, no. 1, pp. 92-98, 2009.

[22] C. M. Springer, K. M. Tannert Niang, T. D. Matte, N. Miller, M. T. Bassett, and T. R. Frieden, "Do medical students know enough about smoking to help their future patients? Assessment of New York City fourth-year medical students' knowledge of tobacco cessation and treatment for nicotine addiction," Academic Medicine, vol. 83, no. 10, pp. 982-989, 2008.

[23] T. F. Heatherton, L. T. Kozlowski, R. C. Frecker, and K.-O. Fagerstrom, "The Fagerstrom test for nicotine dependence: a revision of the Fagerstrom Tolerance Questionnaire," British Journal of Addiction, vol. 86, no. 9, pp. 1119-1127, 1991.

[24] N. J. Fiel, “The lecture: increasing student learning," Journal of Medical Education, vol. 51, no. 6, pp. 496-499, 1976.

[25] M. de Lourdes Vieira Frujeri and E. D. Costa Jr., "Effect of a single dental health education on the management of permanent avulsed teeth by different groups of professionals," Dental Traumatology, vol. 25, no. 3, pp. 262-271, 2009.

[26] M. R. Deluhery, E. B. Lerner, R. G. Pirrallo, and R. B. Schwartz, "Paramedic accuracy using SALT triage after a brief initial training," Prehospital Emergency Care, vol. 15, no. 4, pp. 526532, 2011.

[27] A. A. Patkar, K. Hill, V. Batra, M. J. Vergare, and F. T. Leone, "A comparison of smoking habits among medical and nursing students," Chest, vol. 124, no. 4, pp. 1415-1420, 2003. 
[28] M. J. White, B. M. Ewy, J. Ockene et al., "Basic skills for working with smokers: a pilot test of an online course for medical students," Journal of Cancer Education, vol. 22, no. 4, pp. 254258, 2007.

[29] K. E. Hauer, P. A. Carney, A. Chang, and J. Satterfield, "Behavior change counseling curricula for medical trainees: a systematic review," Academic Medicine, vol. 87, no. 7, pp. 956-968, 2012.

[30] D. Stolz, W. Langewitz, A. Meyer et al., "Enhanced didactic methods of smoking cessation training for medical students: a randomized study," Nicotine and Tobacco Research, vol. 14, no. 2, pp. 224-228, 2012.

[31] T. Raupach, J. Brown, S. Anders, G. Hasenfuss, and S. Harendza, "Summative assessments are more powerful drivers of student learning than resource intensive teaching formats," BMC Medicine, vol. 11, article 61, 2013. 


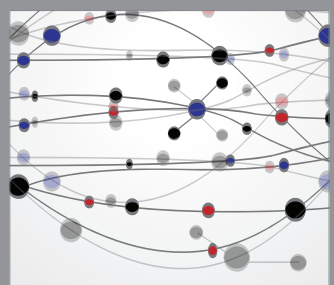

The Scientific World Journal
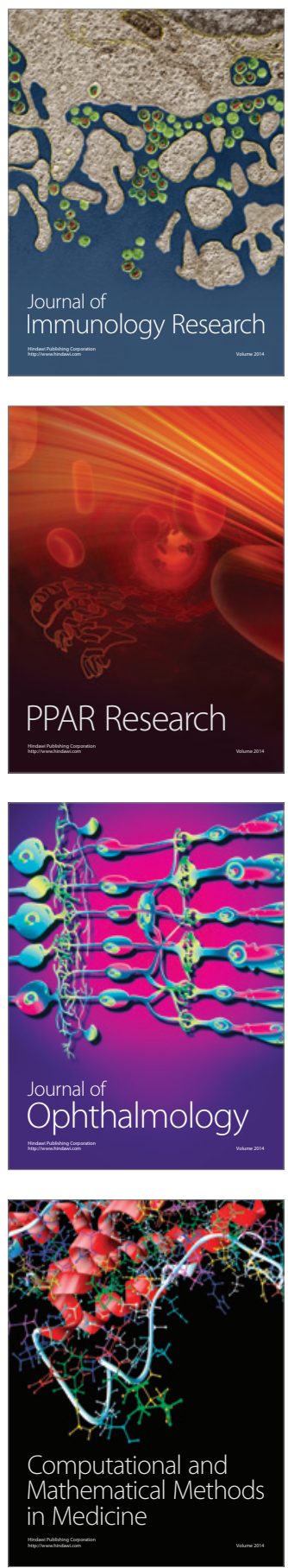

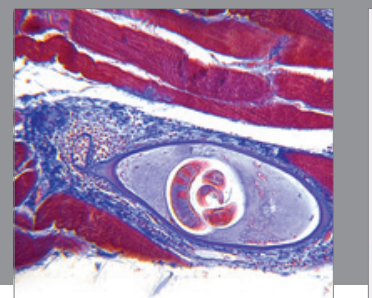

Gastroenterology

Research and Practice
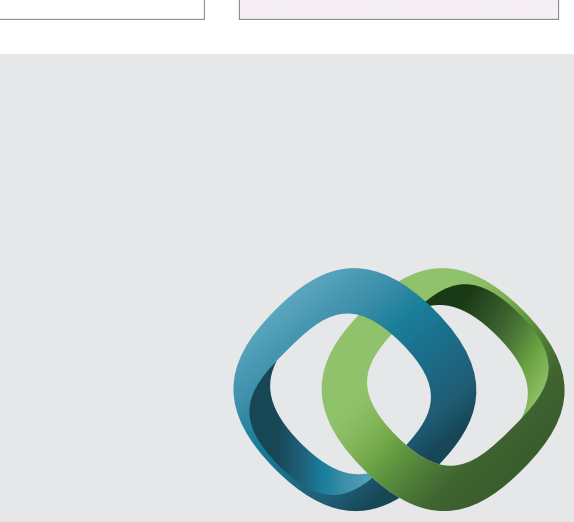

\section{Hindawi}

Submit your manuscripts at

http://www.hindawi.com
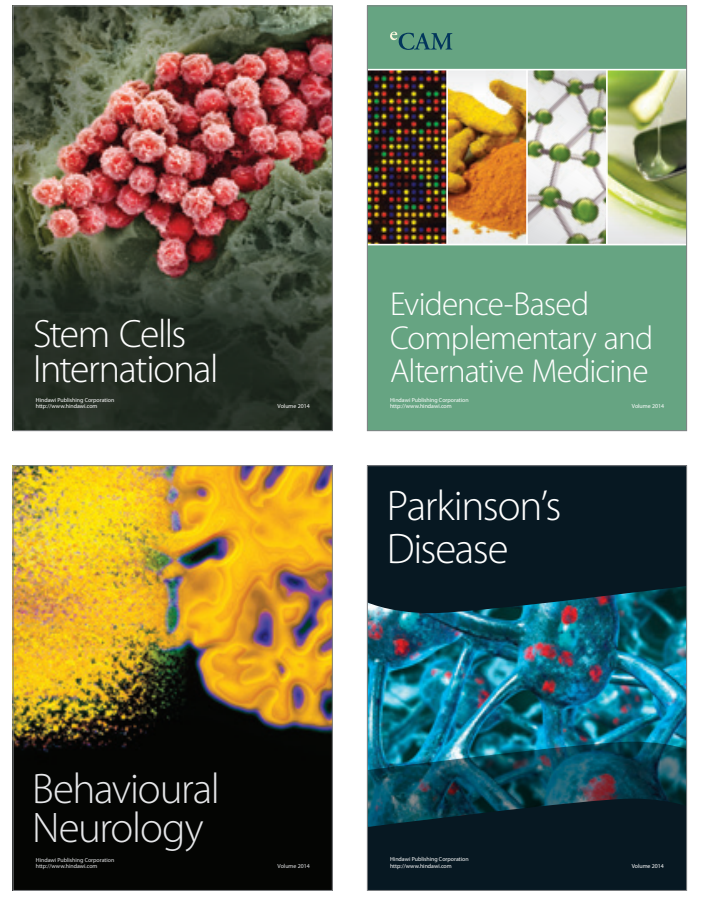
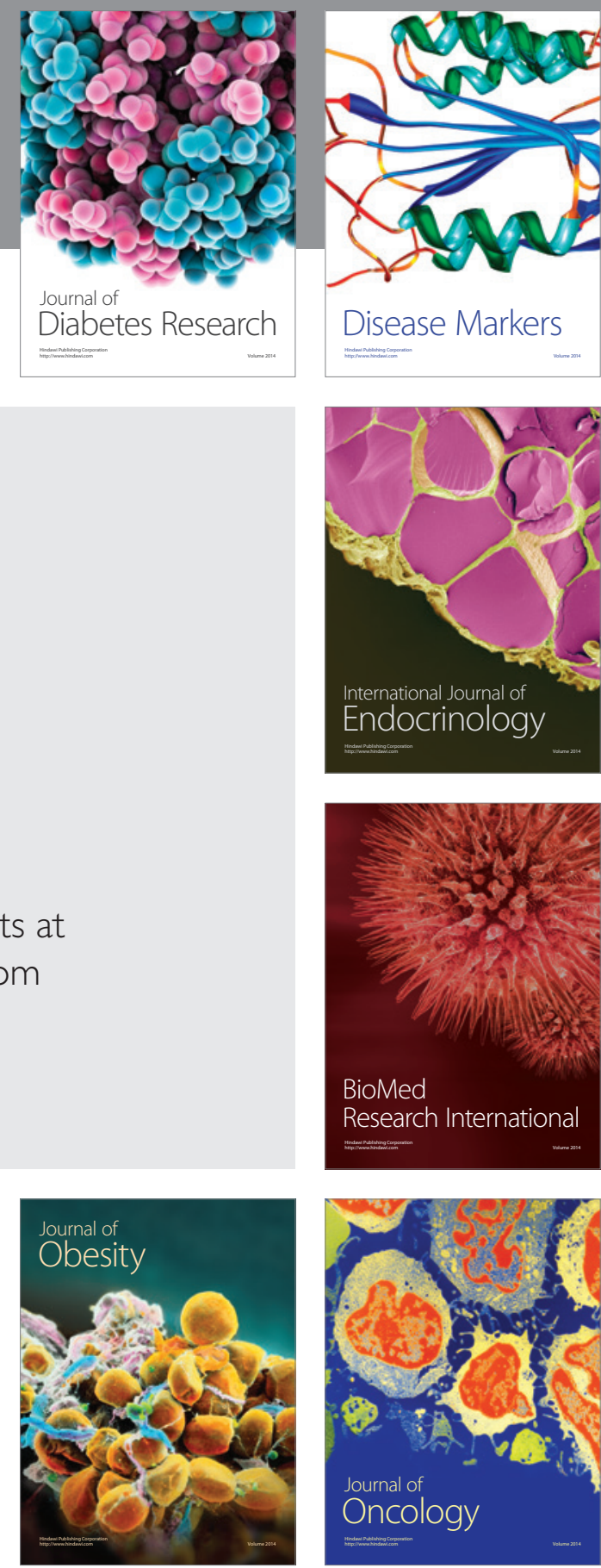

Disease Markers
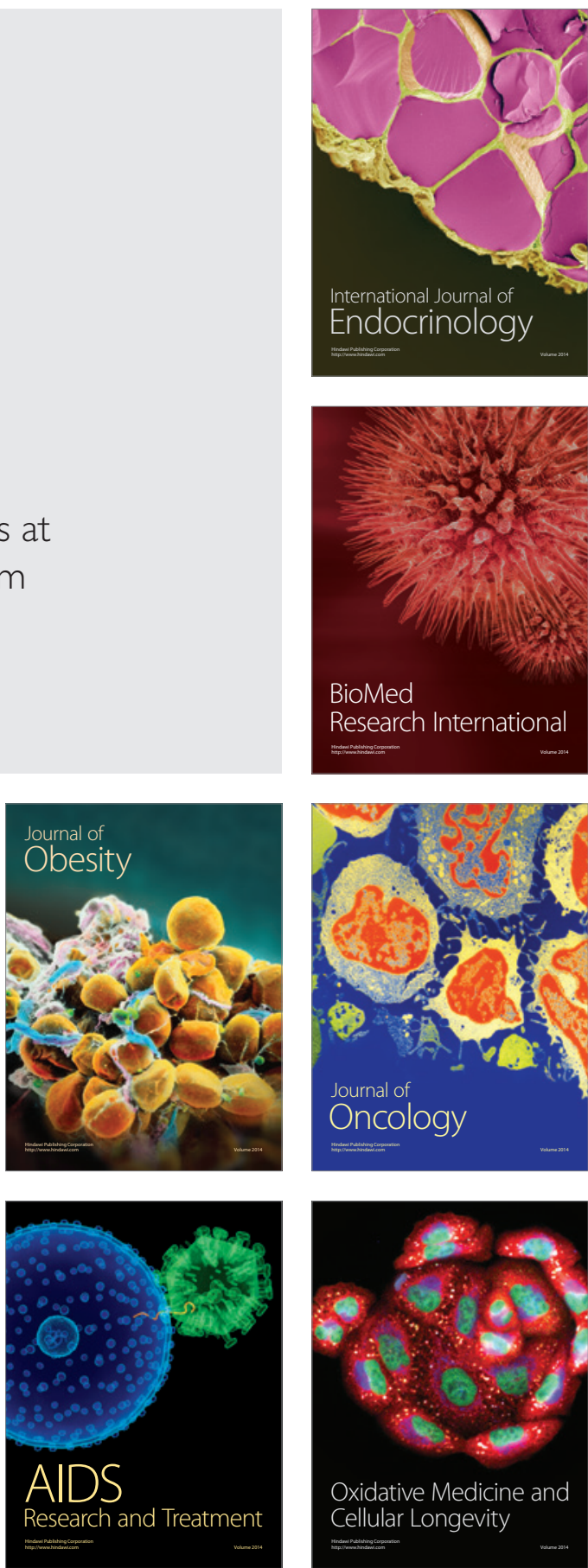